\title{
Residual Stroke Risk in Patients with Atrial Fibrillation Treated with Non-Vitamin K Oral Anticoagulants: An 8-Year Retrospective Cohort Study
}

\author{
Cheuk Ling Charing Szeto Kwok Fai Hui
}

United Christian Hospital, Hong Kong, China

\section{Keywords}

Acute stroke · Anticoagulants · Asian stroke pattern · Atrial fibrillation

\begin{abstract}
Background: Use of non-vitamin $\mathrm{K}$ antagonist oral anticoagulants (NOACs) for stroke prevention in non-valvular atrial fibrillation (NVAF) is common and significantly reduces stroke occurrence. Yet little is known about patients who have a stroke despite treatment. Objective: The aim of this work was to study the epidemiology of patients with stroke despite being treated with NOACs. Methods: We identified a cohort of patients with NVAF admitted to the United Christian Hospital for acute ischemic stroke (AIS) or transient ischemic attack (TIA) while on NOACs. The baseline characteristics, type of NOAC, compliance, duration of use, and dosage were reviewed. Results: Of 2,090 patients admitted for AIS/ TIA from 2012 to 2019, 143 were on NOACs before the index episode. After excluding patients with non-compliance and incomplete data, 109 patients were included in the analysis; $65.1 \%$ were female and $79.8 \%$ were never smokers, with a mean age of 78 years. The mean CHA2DS2-VASc score was $5 ; 83.5 \%$ had hypertension, $59.3 \%$ had hyperlipidemia, and $30.3 \%$ had diabetes mellitus. Overall, $52.9 \%$ presented with lacunar syndrome, suggesting an atherosclerotic cause of stroke. However, their risk factor control was unexpectedly
\end{abstract}

good; none had $\mathrm{HbA} 1 \mathrm{c}>7 \%$ and only $23.9 \%$ had a low-density lipoprotein cholesterol level higher than $2.6 \mathrm{mmol} / \mathrm{L}$. Conclusions: Stroke developed in NVAF patients despite being on NOACs, with the majority being female, older, and hypertensive. Surprisingly, in general they had reasonable lipid and diabetic control.

(C) 2021 The Author(s)

Published by S. Karger AG, Basel

\section{Introduction}

Up to a third of ischemic strokes are caused by atrial fibrillation (AF) [1]. Since the establishment of the superiority of anticoagulation over antiplatelets in cardioembolic stroke prevention [2], along with the awareness of the importance of early detection of AF and introduction of non-vitamin $\mathrm{K}$ antagonist oral anticoagulants (NOACs), stroke prevention has come a long way and the outlook is optimistic $[3,4]$.

However, despite our best efforts in preventing stroke in patients with AF, there is still a substantial number of patients who develop embolic events despite being started on NOACs (1-year standardized absolute risks of stroke/thromboembolism is $1.73-1.98 \%$ and $2.51-2.78 \%$ with standard and reduced NOAC doses, respectively) [5]. Yet little is known regarding the cause of the residual stroke risk, not to mention the subsequent management.
(C) 2021 The Author(s)

Published by S. Karger AG, Basel

This article is licensed under the Creative Commons AttributionNonCommercial-NoDerivatives 4.0 International License (CC BYNC-ND) (http://www.karger.com/Services/OpenAccessLicense) Usage and distribution for commercial purposes as well as any distribution of modified material requires written permission.
Cheuk Ling Charing Szeto

United Christian Hospital

130 Hip Woo Street

Kwun Tong, Hong Kong, SAR S1103 (China)

charingszeto@gmail.com 
Table 1. Definitions of history/risk factors

\begin{tabular}{ll}
\hline Hypertension & Treated or detected persistent hypertension from previous consultations $(\mathrm{BP}>140 / 90 \mathrm{~mm}$ Hg $)$ \\
\hline Diabetes mellitus & $\begin{array}{l}\text { Treated or detected fasting glucose } \geq 126 \mathrm{mg} / \mathrm{dL}(7.0 \mathrm{mmol} / \mathrm{L}) \text {, or plasma glucose } \geq 200 \mathrm{mg} / \mathrm{dL} \\
(11.1 \mathrm{mmol} / \mathrm{L}) \text { after glucose load in the oral glucose tolerance test, or glycated hemoglobin } \geq 6.5 \%\end{array}$ \\
\hline Hyperlipidemia & $\begin{array}{l}\text { Treated or detected total cholesterol } \geq 200 \mathrm{mg} / \mathrm{dL}(5.2 \mathrm{mmol} / \mathrm{L}), \text { or LDL cholesterol } \geq 130 \mathrm{mg} / \mathrm{dL}(3.4 \\
\mathrm{mmol} / \mathrm{L})\end{array}$ \\
\hline Ischemic heart disease & $\begin{array}{l}\text { History of angina pectoris, myocardial infarction, or evidence of coronary artery disease from } \\
\text { angiography }\end{array}$ \\
\hline Congestive heart failure & Clinical history of cardiac failure or echocardiography with ejection fraction $<45 \%$ \\
\hline
\end{tabular}

This retrospective cohort aims to reveal the epidemiology and clinical features of this target group in hope of shedding light on how to identify them and provide better stroke prevention.

\section{Methods}

Patients were retrospectively identified by the Clinical Data Analysis and Reporting System (CDARS). All patients aged 18 years or above who had non-valvular AF (NVAF) on NOACs (dabigatran, rivaroxaban, apixaban, or edoxaban) admitted to the United Christian Hospital for acute ischemic stroke (AIS) or transient ischemic attack (TIA) between January 2012 and December 2019 were recruited.

AIS was defined as "a clinical syndrome characterized by rapidly developing clinical syndromes and/or signs, and at times global loss of cerebral function, with symptoms lasting more than $24 \mathrm{~h}$ or leading to death, with no apparent cause other than a vascular one." TIA was defined as a transient episode of neurological deficit that was not associated with permanent cerebral infarction $[6,7]$.

Clinical notes were reviewed and those with incomplete data or an uncertain diagnosis of stroke were excluded. Demographic and clinical data including age, sex, body weight, smoking status, creatinine level, clotting profile on admission, metabolic risk factors and their controls (definitions listed in Table 1) were obtained.

For the purposes of this study, types of AF were classified as paroxysmal (for AF that terminates spontaneously, usually within 7 days) or sustained (for persistent/permanent AF). Persistent AF was defined as AF requiring pharmacological or electrical cardioversion or lasting $>7$ days, while permanent $\mathrm{AF}$ was defined as $\mathrm{AF}$ that cannot be terminated by cardioversion or is long standing (>1 year) [8]. The type and dosage of the NOACs used were recorded. Whether the patient was put on the correct dosage was evaluated according to the manufacturer's labelling of each specific NOAC. A patient was considered underdosed if they were put on a reduced dose without meeting the dose-reduction criteria. Compliance and the reason for non-compliance were reviewed based on the documentation by the physician-in-charge of clinical notes.

Concomitant antiplatelet use and the use of drugs that potentially cause drug-drug interactions with NOACs (P-glycoprotein inducers, strong CYP-3A4 inducer) were documented. The baseline $\mathrm{CHA}_{2} \mathrm{DS}_{2}$-VASc score before the index admission was calcu- lated ( 2 points for a history of stroke or age $>75$ years, and 1 point each for congestive heart failure, hypertension, diabetes mellitus, vascular disease, age between 65 and 74 years, and female).

The type of stroke - TIA, non-fatal, or fatal - was documented. Clinically, the stroke was classified into lacunar or cortical stroke. The premorbid and post-event modified Rankin Scale (mRS) scores were calculated retrospectively based on the outcome documented by physiotherapists.

Standard descriptive statistics were used to describe the variables collected. Categorical variables were presented as raw numbers and percentages. We used multiple logistic regression to identify factors affecting the outcome in terms of the post-stroke mRS. The Kaplan-Meier method was used to compare the normal dose versus reduced dose of the NOAC group.

\section{Results}

Over the 8-year study period, 2,090 patients admitted for AIS/TIA were screened from the electronic patient record (Fig. 1). Of these, 1,218 were not on any anticoagulants or antiplatelets, 556 were on antiplatelets alone, and 165 were on warfarin. In total, 151 patients who were on NOACs before the index episode were included. Three patients with incomplete data and 5 patients with an uncertain diagnosis (e.g., non-specific weakness and numbness) were excluded. Also, 34 patients who were non-compliant to NOACs were excluded from the statistical analysis.

Of the 109 patients included from January 2012 to December $2019,65.1 \%$ were female and the mean age was 78.1 years (range $45-92)$. The majority $(79.8 \%)$ were never smokers, and only $4.5 \%$ were active smokers. The mean body weight was $59.3 \mathrm{~kg}$.

All were put on NOACs before admission: the majority were on rivaroxaban (44\%) or dabigatran (41.2\%). Up to $68.8 \%$ were on a reduced dose, amongst which $28.4 \%$ were underdosed (11 for bleeding risk, 12 for advanced age, and 8 for unspecified reasons). Overall, 23.8\% (34/143) were non-compliant to NOACs: 5 stopped med-
Szeto/Hui 
Fig. 1. Number of patients screened, excluded, and eventually included for analysis. In total, 2,090 patients admitted to the United Christian Hospital for AIS/TIA were screened from the CDARS; 1,939 patients were excluded for not being treated with NOACs, and 52 were excluded due to non-compliance, incomplete data, and an uncertain diagnosis. Eventually, 109 patients were included for analysis.

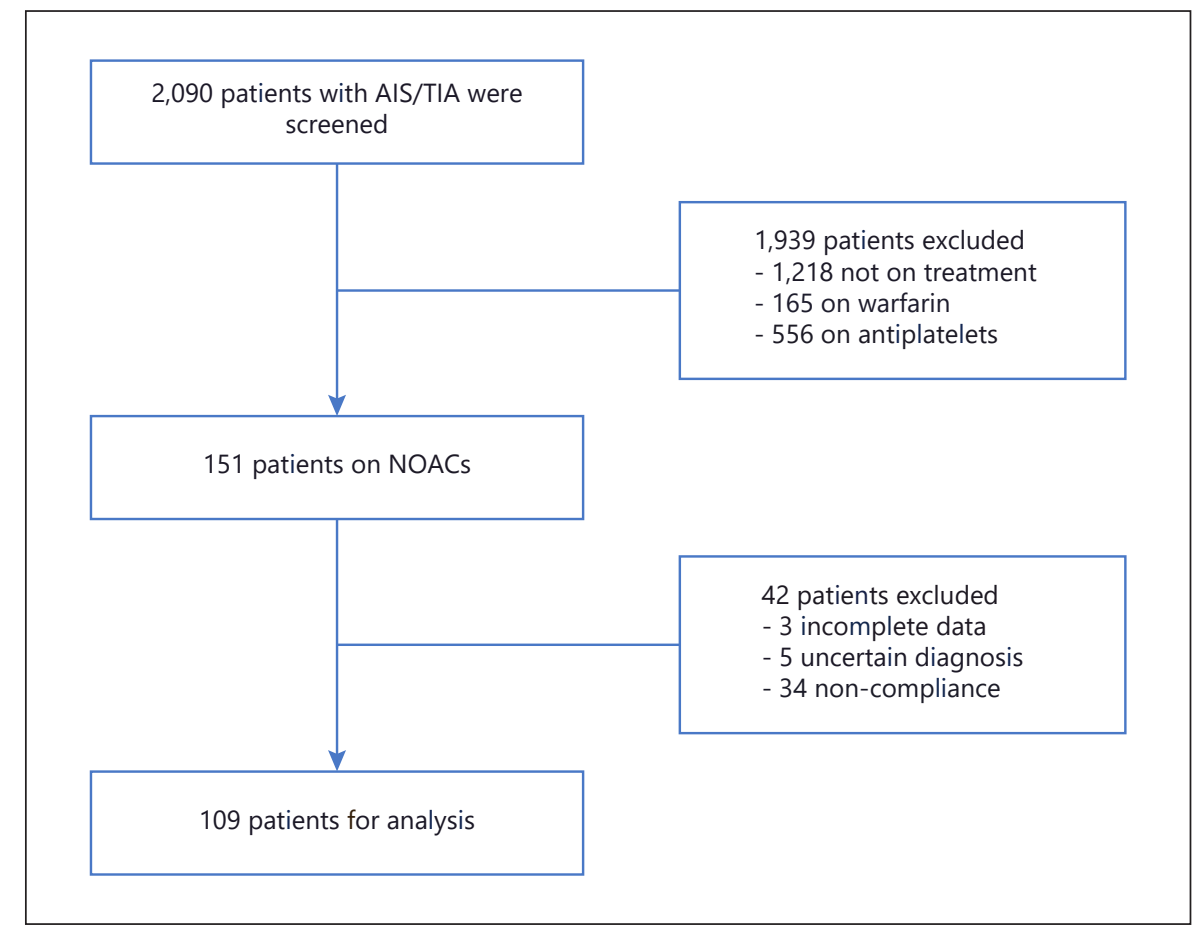

Fig. 2. Distribution of scores on the mRS for premorbid cases and after discharge. Around half (47.8\%) of patients' baseline scores were $<3$ (walking unassisted), while the scores of $72.5 \%$ became higher than 4 (walking with assistance or bedridden or dead) upon discharge. Fatal stroke accounted for $11.1 \%$.

ication for dental or surgical procedures with a duration of more than required, 5 did not take the medication or were taking medication in half doses due to financial constraints, 5 due to forgetfulness, 3 due to intolerance, 3 due to bleeding symptoms (including hematuria, post-menopausal bleeding), and 13 for unspecified reasons.

For baseline cardiovascular risk factors (Table 2), $83.5 \%$ had hypertension, $30.3 \%$ had diabetes mellitus,
$59.3 \%$ had hyperlipidemia, and $59.6 \%$ had a history of stroke or TIAs before this admission. The mean $\mathrm{CHA}_{2} \mathrm{DS}_{2^{-}}$ VASc score was 5.

Vascular imaging was performed in 32.1\% (35/109; including either ultrasound, carotid and transcranial ultrasound, computed tomography angiography, or magnetic resonance angiography of cerebral and carotid arteries). Amongst them, 11.4\% (4/35) had significant (i.e., moderate 
Table 2. Baseline characteristics $(n=109)$

\begin{tabular}{|c|c|}
\hline & $n(\%)$ \\
\hline \multicolumn{2}{|l|}{ Baseline epidemiology } \\
\hline Female & $71(65.1)$ \\
\hline Age $>75$ years & $80(73.4)$ \\
\hline Age $>80$ years & $57(52.2)$ \\
\hline Current smoker & $5(4.5)$ \\
\hline Ex-smoker & $17(15.6)$ \\
\hline Never smoker & $87(79.8)$ \\
\hline \multicolumn{2}{|l|}{ Risk factors } \\
\hline Hypertension & $91(83.5)$ \\
\hline Diabetes mellitus & $33(30.3)$ \\
\hline Hyperlipidemia & $64(59.3)$ \\
\hline Peripheral vascular disease & $4(3.7)$ \\
\hline Ischemic heart disease & $31(28.4)$ \\
\hline Congestive heart failure & $8(7.4)$ \\
\hline History of stroke/TIA & $65(59.6)$ \\
\hline \multicolumn{2}{|l|}{ Chronic kidney disease } \\
\hline Stage I $(\mathrm{GFR} \geq 90 \mathrm{~mL} / \mathrm{min})$ & $15(13.8)$ \\
\hline Stage II (GFR $60-89 \mathrm{~mL} / \mathrm{min})$ & $47(43.1)$ \\
\hline Stage III (GFR $30-59 \mathrm{~mL} / \mathrm{min}$ ) & $42(38.5)$ \\
\hline Stage IV (GFR $15-29 \mathrm{~mL} / \mathrm{min}$ ) & $5(4.6)$ \\
\hline \multicolumn{2}{|l|}{ Type of AF } \\
\hline Paroxysmal AF & $28(25.7)$ \\
\hline Sustained AF & $81(74.3)$ \\
\hline \multicolumn{2}{|l|}{ Type of NOACs } \\
\hline Dabigatran & $45(41.2)$ \\
\hline Rivaroxaban & $48(44.0)$ \\
\hline Apixaban & $16(14.7)$ \\
\hline \multicolumn{2}{|l|}{ Dosing of NOACs } \\
\hline Reduced dose & $75(68.8)$ \\
\hline Off-label reduced dose & $49(45.0)$ \\
\hline \multicolumn{2}{|l|}{ Concomitant drug use } \\
\hline P-glycoprotein inducers/strong & \\
\hline CYP-3A4 inducer & $2(1.8)$ \\
\hline Antiplatelets (aspirin/clopidogrel) & $6(5.5)$ \\
\hline
\end{tabular}

to severe) stenosis intracranially and extracranially, $28.6 \%$ $(10 / 35)$ had significant intracranial stenosis, $14.3 \%(5 / 35)$ had significant extracranial stenosis, and $45.7 \%(16 / 35)$ had no or merely mild stenosis intra- or extracranially.

For risk factor control, only $23.9 \%$ had low-density lipoprotein (LDL) cholesterol higher than $2.6 \mathrm{mmol} / \mathrm{L}$, $72.5 \%$ were on statins, and none had glycated hemoglobin (HbA1c) higher than 7\%. Of all the ischemic events, 7.3\% experienced TIA, $52.3 \%$ presented with lacunar syndrome, and $35.8 \%$ with cortical symptoms, of which $11.0 \%$ were fatal stroke (Fig. 2).

While there was a tendency of higher survival for patients on normal doses versus those on reduced doses (with both correctly reduced or incorrectly underdosed included), it was not statistically significant ( $p=0.579$ ).
Similarly, there was a trend of higher survival when compared with those on the correct dose versus those who were underdosed; however, this was also not statistically significant ( $p=0.752$; Fig. 3 ).

\section{Discussion}

In our study of 2,090 cardioembolic AIS/TIA patients, $0.67 \%$ of them had already been put on NOACs. The reason for the failure of the prevention of stroke was not certain. To date, clinical data are still lacking to guide our management. This cohort study aimed to address this particular group of patients and explore their characteristics.

Compliance had long been an issue for warfarin. However, the problem of compliance remained despite the use of NOACs [9]. In our cohort, around one-fifth were incompliant with NOACs. The reasons for non-compliance included mild bleeding (e.g., gum bleeding, hematuria), prematurely withholding medication before dental or surgical procedures, forgetfulness, and financial reasons. In our locality, NOACs were self-financed items when they were first launched. Since 2019, they have been subsidized for high thrombotic risk patients, that is, those with a $\mathrm{CHA}_{2} \mathrm{DS}_{2}$-VASc score higher than or equal to 5 . This has partly improved the compliance issue and increased the prevalence of use of NOACs in our locality.

A reduced dose was prescribed in up to $62.2 \%$ of patients in our cohort. It is common for Asian patients to be put on a reduced dose due to general lower body weights. Moreover, off-label reduced dosing is a common problem, especially in Asia [10]. In our cohort, up to $45 \%$ were put on off-label reduced doses. The reasons for reduced doses included advanced age, bleeding risks, impaired renal function (but not yet to the level requiring dose reduction), and so on. Other cohorts have also described off-label reduced doses as a risk factor for recurrent stroke [11].

Those who developed stroke despite adequate anticoagulation had other concomitant atherosclerotic risk factors that were attributed to the failure of preventing stroke [12]. From our cohort, more than half had concomitant hypertension or hyperlipidemia.

To our surprise, the majority of these patients developed stroke despite a relatively good control of such risk factors: none had poor diabetes control (all had $\mathrm{HbAlc}$ $<7 \%$ ), and up to $84.4 \%$ had LDL cholesterol $<2.6 \mathrm{mmol} / \mathrm{L}$ and most were never smokers $(79.8 \%)$. It would be of interest to observe the impacts of more stringent controls of atherosclerotic risk factors being required of patients with AF.
Szeto/Hui 


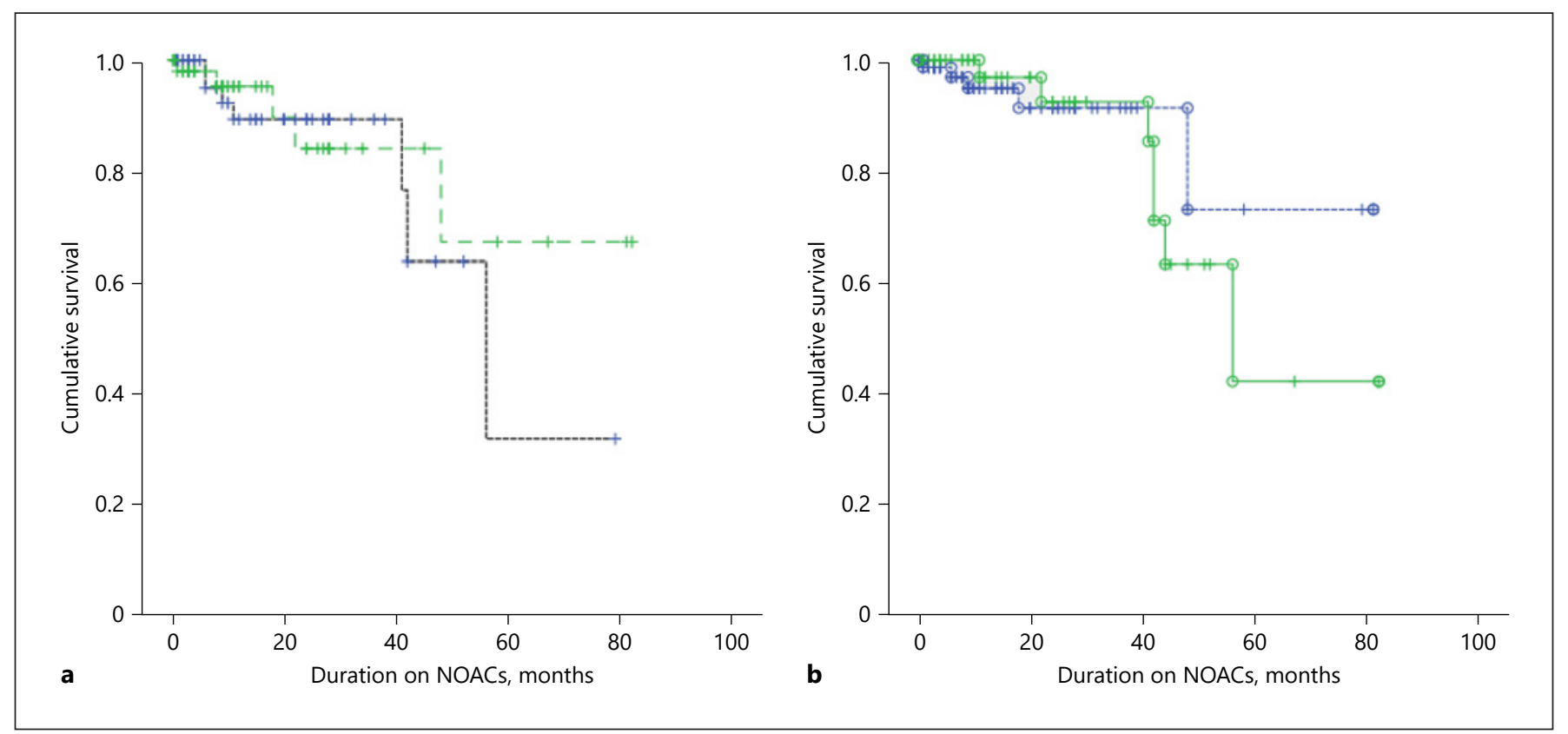

Fig. 3. Kaplan-Meier curve for AF patients on a normal dose versus a reduced dose. a The black dashed line depicts the survival curve for patients on NOACs with a reduced dose while the green dashed line represents the survival curve for patients on a normal dose. There was a trend of higher survival for patients on a normal dose; however, it was not statistically significant $(p=0.579)$. b The green

It is worth noting that the majority of the ischemic events were mainly presented as lacunar syndrome in our cohort (52.9\%), suggesting a possible non-cardioembolic cause of stroke [13]. As studies have pointed out, not all stroke events in AF patients are cardioembolic, and 17.2\% of strokes are classified as unrelated to AF [14]. However, the majority of our patients did not have angiograms or echocardiograms performed, hence we could not determine the mechanism of stroke for our cohort. Only a third of cases had angiograms conducted at some point, among which around half had significant intra- and/or extracranial artery stenosis. It represented a group of patients in which anticoagulation alone may not be adequate for stroke prevention.

Nonetheless, an overwhelmingly low percentage of patients were put on antiplatelets - only $5.5 \%$ - all of whom were put on additional antithrombotics due to the indication of acute coronary syndrome or post-percutaneous coronary intervention (PCI). Over the past decade, the management with antithrombotics of patients with $\mathrm{AF}$ and recent acute coronary syndrome and/or PCI has advanced, with multiple clinical trials like the PIONEER-AF PCI trial in 2016 and the AUGUSTUS trial in 2019. Both

solid line depicts the survival curve for patients on NOACs who were incorrectly underdosed, while the blue dashed line represents the survival curve for patients on the correct dose. There was a trend of higher survival for correctly dosed patients; however, it was not statistically significant $(p=0.752)$.

demonstrated the safety of NOACs with single antithrombotics use and lower bleeding risk compared to warfarin-based treatments $[15,16]$. However, the benefit of add-on antiplatelet therapy for such groups of patients for atherosclerotic stroke risk is uncertain and needs to be balanced against bleeding risk [17].

There are several limitations of this study. Firstly, this was a single-center study with a limited sample size. Secondly, the study was observational and retrospective. Data were extracted from electronic documentations recorded by the physician in charge. Results were only available online and private images were not retrieved. Also, non-compliance may have been underestimated due to reporting bias.

Regarding the strengths of our study, it is the first in our locality to consider the epidemiology of patients who suffer stroke despite being on NOACs. It included all patients since the popularization of the use of NOACs in Hong Kong, in which it reflected the real-life experience of managing such a group of patients. Further studies investigating the benefits of more stringent risk factor control and the value of add-on antiplatelets for at-risk patients are warranted. 


\section{Conclusion}

In NVAF patients on NOACs with AIS/TIA, the majority were female, older than 75 years, on a reduced dose of NOACs, hypertensive, and with a history of AIS/TIA. Unfortunately, they developed stroke despite being nonsmokers and having good diabetic and lipid control.

\section{Statement of Ethics}

This is a retrospective cohort study where only patients' medical records were reviewed without any medical intervention or alteration to the current management of recruited patients. The research data did not record the identity of any patients. Hence, consent was not obtained. This study was approved by the Research Ethics Committee (Kowloon Central/Kowloon East), reference No. KC/KE-20-0025/ER-3.

\section{Conflict of Interest Statement}

The authors have no conflicts of interest to declare.

\section{Funding Sources}

There are no funding sources to declare.

\section{Author Contributions}

Dr. Cheuk Ling Charing Szeto collected statistical data, analyzed results, and drafted the paper. Dr. Kwok Fai Hui revised and approved the final version to be published. Both parties agreed to be accountable for all aspects of the work.

\section{References}

1 Wolf PA, Abbott RD, Kannel WB. Atrial fibrillation as an independent risk factor for stroke: the Framingham Study. Stroke. 1991 Aug;22(8):983-8.

2 van Walraven C, Hart RG, Singer DE, Laupacis A, Connolly S, Petersen P, et al. Oral anticoagulants vs aspirin in nonvalvular atrial fibrillation: an individual patient meta-analysis. JAMA. 2002 Nov;288(19):2441-8.

3 Ruff CT, Giugliano RP, Braunwald E, Hoffman EB, Deenadayalu N, Ezekowitz MD, et al. Comparison of the efficacy and safety of new oral anticoagulants with warfarin in patients with atrial fibrillation: a meta-analysis of randomised trials. Lancet. 2014 Mar;383(9921): 955-62.

4 Huisman MV, Rothman KJ, Paquette M, Teutsch C, Diener HC, Dubner SJ, et al.; GLORIA-AF Investigators. The changing landscape for stroke prevention in AF: findings from the GLORIA-AF registry phase 2. J Am Coll Cardiol. 2017 Feb;69(7):777-85.

5 Staerk L, Gerds TA, Lip GY, Ozenne B, Bonde AN, Lamberts M, et al. Standard and reduced doses of dabigatran, rivaroxaban and apixaban for stroke prevention in atrial fibrillation: a nationwide cohort study. J Intern Med. 2018 Jan;283(1):45-55.

6 Sacco RL, Kasner SE, Broderick JP, Caplan LR, Connors JJ, Culebras A, et al. An updated definition of stroke for the 21st century: a statement for healthcare professionals from the American Heart Association/American Stroke Association. Stroke. 2013 Jul;44(7): 2064-89.

7 Easton JD, Saver JL, Albers GW, Alberts MJ, Chaturvedi S, Feldmann E, et al. Definition and evaluation of transient ischemic attack: a scientific statement for healthcare professionals from the American Heart Association/ American Stroke Association Stroke Council; Council on Cardiovascular Surgery and Anesthesia; Council on Cardiovascular Radiology and Intervention; Council on Cardiovascular Nursing; and the Interdisciplinary Council on Peripheral Vascular Disease. Stroke. 2009 Jun;40(6):2276-93.

8 Senoo K, Lip GY, Lane DA, Büller HR, Kotecha D. Residual risk of stroke and death in anticoagulated patients according to the type of atrial fibrillation: AMADEUS Trial. Stroke. 2015 Sep;46(9):2523-8.

9 Liu C, Du X, Jiang C, He L, Chang SS, Guo XY, et al. Long-term persistence with newly-initiated warfarin or non-VKA oral anticoagulant (NOAC) in patients with non-valvular atrial fibrillation: insights from the prospective China-AF registry. Med Sci Monit. 2019 Apr; 25:2649-57.

10 Cho MS, Yun JE, Park JJ, Kim YJ, Lee J, Kim $\mathrm{H}$, et al. Pattern and Impact of Off-label Underdosing of Non-Vitamin K Antagonist Oral Anticoagulants in Patients With Atrial Fibrillation Who are Indicated for Standard Dosing. Am J Cardiol. 2020 May;125(9):1332-8.

11 Paciaroni M, Agnelli G, Caso V, Silvestrelli G, Seiffge DJ, Engelter S, et al. Causes and Risk Factors of Cerebral Ischemic Events in $\mathrm{Pa}$ tients With Atrial Fibrillation Treated With Non-Vitamin K Antagonist Oral Anticoagulants for Stroke Prevention. Stroke. 2019 Aug; 50(8):2168-74.

12 Freedman B, Martinez C, Katholing A, Rietbrock S. Residual risk of stroke and death in anticoagulant-treated patients with atrial fibrillation. JAMA Cardiol. 2016 Jun;1(3):3668.

13 Arboix A, Alió J. Cardioembolic stroke: clinical features, specific cardiac disorders and prognosis. Curr Cardiol Rev. 2010 Aug;6(3): $150-61$.

14 Kim SJ, Ryoo S, Kwon S, Park YK, Kim JP, Lee GY, et al. Is atrial fibrillation always a culprit of stroke in patients with atrial fibrillation plus stroke? Cerebrovasc Dis. 2013;36:37382.

15 Gibson CM, Mehran R, Bode C, Halperin J, Verheugt F, Wildgoose P, et al. An open-label, randomized, controlled, multicenter study exploring two treatment strategies of rivaroxaban and a dose-adjusted oral vitamin $\mathrm{K}$ antagonist treatment strategy in subjects with atrial fibrillation who undergo percutaneous coronary intervention (PIONEER AF-PCI). Am Heart J. 2015 Apr;169(4):472-8.e5.

16 Lopes RD, Vora AN, Liaw D, Granger CB, Darius H, Goodman SG, et al. An open-Label, $2 \times 2$ factorial, randomized controlled trial to evaluate the safety of apixaban vs. vitamin $\mathrm{K}$ antagonist and aspirin vs. placebo in patients with atrial fibrillation and acute coronary syndrome and/or percutaneous coronary intervention: rationale and design of the AUGUSTUS trial. Am Heart J. 2018 Jun;200:17-23.

17 Kumar S, Danik SB, Altman RK, Barrett CD, Lip GY, Chatterjee S, et al. Non-Vitamin K Antagonist Oral Anticoagulants and Antiplatelet Therapy for Stroke Prevention in Patients With Atrial Fibrillation: A Meta-Analysis of Randomized Controlled Trials. Cardiol Rev. 2016 Sep-Oct;24(5):218-23. 